\title{
Occurrence of Chaceon fenneri (Manning \& Holthuis) (Crustacea, Brachyura, Geryonidae) in the Northeast of Brazil
}

\author{
Cheruparambil Sankarankutty ${ }^{1,2}$ \\ Alexander C. Ferreira ${ }^{2}$ \\ Jorge E. Lins Oliveira ${ }^{2}$ \\ Kenya M.F. Cunha ${ }^{2}$
}

\begin{abstract}
Chaceon fenneri (Manning \& Holthuis, 1984), so far known only from the offshore region of Florida, was collected off the Northeast of Brazil. A discussion on the variation within the species and morphometric data of the specimens examined are also given.

KEY WORDS. Chaceon fenneri, occurrence, Northeast Brazil
\end{abstract}

Of a total of 28 species of Chaceon Manning \& Holthuis, 1989 so far described (eight species from the Pacific Ocean, five species from the Indian Ocean and 15 from the Atlantic Ocean), six species occur in the Western Atlantic (MANNING \& HolthUIS 1984, 1986, 1989; MANNING et al. 1989). They are: C. eldorado Manning \& Holthuis, C. fenneri (Manning \& Holthuis, 1984), C. inghami (Manning $\&$ Holthuis), C. notialis Manning \& Holthuis, C. quinquedens (Smith) and C. ramosae Manning, Tavares \& Albuquerque.

MANNING \& Holthuis (1984), described Geryon fenneri to designate the material collected off the east coast of Florida. Subsequently, MANNING \& HoLTHUIS (1989) erected a new genus Chaceon to accommodate the species G. fenneri and five other species until then assigned to the genus Geryon Kroyer. During a survey of the fishery resources of the northeast region of Brazil in 1997 by R.V. Natureza $\left(1.5^{\circ} \mathrm{S}-4.0^{\circ} \mathrm{S} ; 34.0^{\circ} \mathrm{W}-42.0^{\circ} \mathrm{W}\right)$, several specimens of $C$. fenneri were collected using large lobster traps. The present finding extends its known range further south.

Abbreviations used: (cl) carapace length, $(\mathrm{cb})$ carapace breadth.

Remarks. The specimens examined here (a total of 50 specimens, 39 males and rest females) presented the following characteristics: The largest specimen which is a male measured $\mathrm{cl} 146 \mathrm{~mm}$ and $\mathrm{cb} 170 \mathrm{~mm}$; the range of size is between $\mathrm{cl} / \mathrm{cb} 94 / 112$ $\mathrm{mm}$ to $146 / 170 \mathrm{~mm}$; the ratio of $\mathrm{cl} / \mathrm{cb}$ is between 1.10 and 1.21 ; frontal width always is slightly more than orbital width; distance between first and third anteolateral tooth is shorter than distance between third and fifth anterolateral teeth in 36 specimens, in

1) Departamento de Oceanografia e Limnologia, Universidade Federal do Rio Grande do Norte. Praia de Mãe Luiza, Via Costeira, 59014-100 Natal, Rio Grande do Norte, Brasil. E-mail: sankaran@digi.com.br

2) Bolsista do CNPq. 

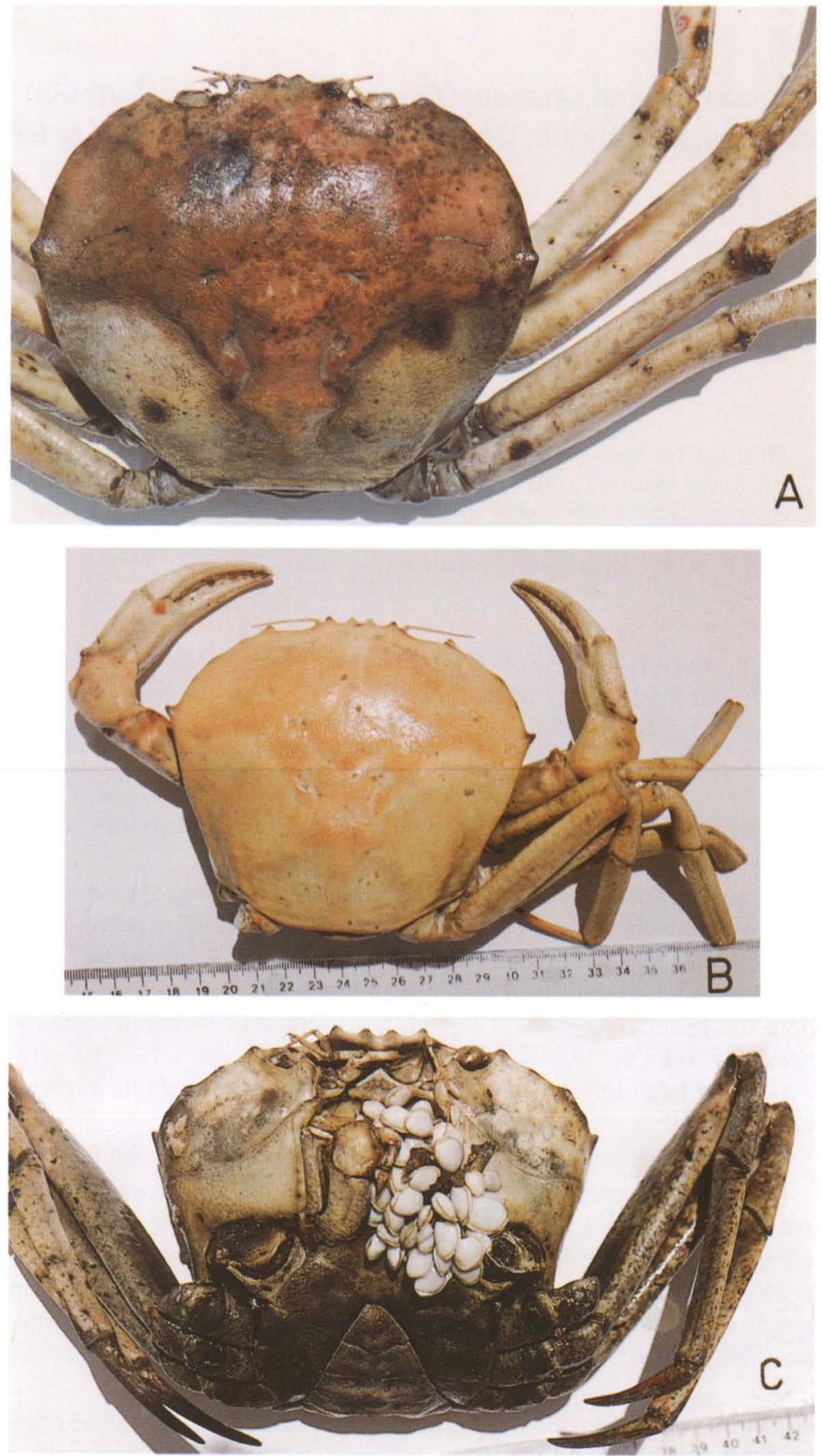

Fig. 1. Chaceon fenneri. (A-B) Dorsal view of a male specimens; (C) a male specimen with octolamid fowling of buccal region. 

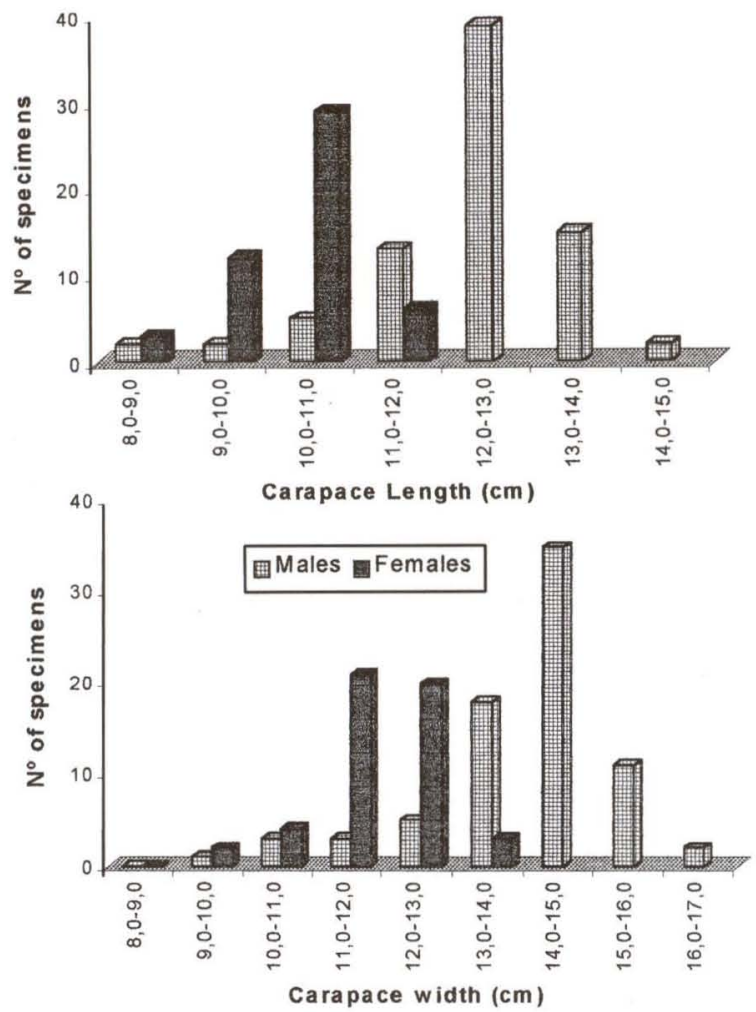

Fig. 2. Morphometric data of the specimens examined.

two specimens the distance is equal and in four specimens the distance between first and third is greater than that between third and fifth; shape, size and disposition of frontal teeth are variable (Fig. 1A, B); of five anterolateral teeth, second and fourth are smallest and often unrecognizable and in large specimens all teeth except fifth are obsolete; dactylus of walking legs is shorter than propodus and laterally compressed; ratio between length and height of merus of fifth walking legs ranges between 3.72 and 5.58 in the males and between 4.25 and 7.66 in the females; ratio between length and height of propodus ranges between 3.46 and 6.2 in the males and between 3.81 and 5.38 in the females. The colouration of the specimens from this region presents wide diversity from dull grey to reddish and lighter yellow (Fig. 1).

The figure 2 shows the size range of the specimens collected, the largest male measured cl. $15.0 \mathrm{~cm}$. and cb. $17.0 \mathrm{~cm}$., and the largest female measured $\mathrm{cl} .8 .0 \mathrm{~cm}$. and $\mathrm{cb} .14 .0 \mathrm{~cm}$.

In view of the fact that the specimens from the same locality present a wide range of variations, not only in their colour but also in their morphological characteristics, it was obvious that a great deal still remains to be done to define the characteristics which can form a firm basis for the separation of the various species so far known. 
Several specimens also showed heavy fowling by the octolamid organisms, one such heavy fouling of the buccal region is shown in the figure 1C.

A representative sample of the material examined are in the collection of Museu do Mar "Onofre Lopes"of Universidade Federal do Rio Grande do Norte, cl. (MMOL 003), a male and female in the collection of Museu de Zoologia MZUSP13707), Universidade de São Paulo and a male and female in the collection of Smithsonian Institution, Washington, D.C.(USNM309757).

ACKNOWLEDGEMENT. This project was carried out during the tenure of a fellowship of the National Council for the Development of Science and Technology $(\mathrm{CNPq})$, Brazil for which we are grateful. Help received from Dr. Raymond Manning in the preparation of this paper is gratefully acknowledged. A comprehensive revision of the manuscript was facilitated through critical evaluation by two anonymous referees and we express our sincere gratitude to them.

\section{REFERENCES}

MANNING, R.B. \& L.B. Holthuis. 1984. Geryon fenneri, a new deepwater crab from Florida (Crustacea: Decapoda: Geryonidae). Proc. Biol. Soc. Wash. 97 (3): 666-673.

- 1986. Notes on Geryon from Bermuda, with the description of Geryon inghami, new species (Crustacea: Decapoda: Geryonidae). Proc. Biol. Soc. Wash. 99 (2): 366-373.

- 1989. Two new genera and nine new species of Geryonid crabs (Crustacea, Decapoda, Geryonidae). Proc. Biol. Soc. Wash. 102 (1): 50-77.

MANNING, R.B.; M.S. TAVARES \& E.F. AlbUQUERQUe. 1989. Chaceon ramosae, a new deep-water crab from Brazil (Crustacea: Decapoda: Geryonidae). Proc. Biol. Soc. Wash. 102 (3): 646-650.

Recebido em 29.VI.2000; aceito em 01.VI.2001. 